Mersin Photogrammetry Journal

https://dergipark.org.tr/en/pub/mephoj

e-ISSN 2687-654X

\title{
Detection of existing infrastructure lines with wearable laser scanners and making infrastructure map: a case of Mersin University
}

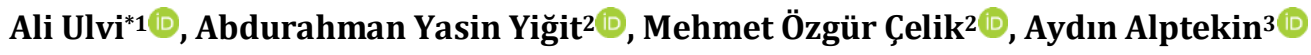 \\ ${ }_{1}^{1}$ Mersin University, Remote Sensing and Geographic Information Systems, Mersin, Turkey \\ ${ }_{2}^{2}$ Mersin University, Geomatics Engineering Department, Mersin, Turkey \\ ${ }^{3}$ Mersin University, Geological Engineering Department, Mersin, Turkey
}

\author{
Keywords \\ WMLS \\ UAV \\ Photogrammetry \\ Point Cloud
}

\begin{abstract}
Technological developments have shown themselves in the field of engineering as in every field. Wearable mobile laser scanner (WMLS) system is a technique based on simultaneous localization and mapping (SLAM) algorithm. This technique enables the creation of a map of an unknown environment bypassing with distance sensors while simultaneously determining the system located on the map. Due to the rapid progress in measurement technology, a heron WMLS has been used in the detection of underground lines. The point cloud of the roads was obtained with the laser scanner. Sewerage, water, and natural gas pipelines were determined through the point cloud. These determinations were checked with a Global Positioning System (GPS) device. As a result of this study, maps of the existing infrastructure lines in the campus were created.
\end{abstract}

\section{Introduction}

Infrastructure facilities are passed under roads and pavements, especially in city centers. Excavation demands that will arise due to the placement of new infrastructure lines, maintenance/repair and improvements of existing lines, capacity increases due to population increases that may arise over time, compulsory situations, etc. and cause various problems in terms of road superstructure (rigid, flexible) and road users (vehicle, pedestrian) (Karataş and Bıyık, 2015).

Information systems are needed in order to take fast and correct decisions as a result of infrastructure map production and to minimize the damages as explained in the aim of the project (Karataş and Bıyık, 2015). The understanding of infrastructure map production has developed with the construction of natural gas lines, however, the necessary importance has not been given fully. However, the production of maps for natural gas lines has also mobilized other infrastructure organizations. Intensive infrastructure works in our country in recent years damage the lines of other infrastructure institutions and these damages result in loss of life and property.

The reasons for these damages are infrastructure organizations do not use maps yet, the absence of maps of the region to be studied, relying on the memory of the people who do the work in the study area, incomplete and incorrect map measurements not updating the maps.

There are places where infrastructure maps are not available, not the Information System. Infrastructure maps are still in the minds of the craftsmen or on papers drawn randomly by underestimating the work done.
* Corresponding Author

*(aliulvi@mersin.edu.tr) ORCID ID 0000-0003-3005-8011 (abdurahmanyasinyigit@gmail.com) ORCID ID 0000-0002-9407-8022

(mozgurcelik@mersin.edu.tr) ORCID ID 0000-0003-4569-888X

(aydinalptekin@mersin.edu.tr) ORCID ID 0000-0002-5605-0758
Ulvi A, Yiğit a Y, Çelik M Ö \& Alptekin A (2021). Detection of existing infrastructure lines with wearable laser scanners and making infrastructure map: a case of Mersin University. Mersin Photogrammetry Journal, 3(2), 61-68 
The quality and efficiency of the infrastructure directly affects the quality of life of people, the healthy functioning of the social system, and the continuity of economic activities. The indicator of a nation's economic development is directly proportional to its infrastructure development. The infrastructure of a city is similar to the circulatory system of the human body. When even the slightest problem occurs in this system, it adversely affects other organs and systems, namely general health and living conditions.

Although there are many definitions of infrastructure, it is often associated with the phrase Public services. When it comes to public services, electricity, waste water, drinking water, natural gas, communication, etc., supplied by the relevant institutions (rather local governments) and developed when needed. Public services, which require a large amount of investment, produce solutions aimed at solving the problems of the public, and the planning, design, manufacturing and management processes are carried out or supervised by the relevant administration. In recent years, information technologies, which are the needs of the age, have been rapidly adopted and used by local governments. The inadequacy of traditional public administration instruments necessitates the effective and essential use of similar technologies in public administration.

Efficient and economical use of resources in the realization of infrastructure services requires effective planning and coordination. Coordinated planning and realization of infrastructure (drinking water, sewage, natural gas, electricity, communication, etc.) and road superstructure (asphalt, pavement, etc.) is of great importance in terms of preventing disruptions in pedestrian and pedestrian traffic and minimizing the damage to the environment.

In order to produce infrastructure maps, existing maps and orthophoto maps are needed. These maps can be produced with technical devices such as unmanned aerial vehicles, laser scanners, GPS and software that works in parallel with this hardware. Literature studies on these technical devices are shown below.

Heron Lite laser scanner is used in many fields, by different professional disciplines. There are studies examining working performance in different regions. Maset et al., (2021/a), investigated the usability and success of the wearable/portable heron lite mobile laser scanner (MLS) in two different outdoor environments. One of these environments; is a large and detailed building (university) that is shown among the standard uses of the heron lite scanner. The other one is the natural environment, where portable systems have not been used yet. The point clouds obtained from these two environments were compared with the reference models provided by traditional techniques (such as Terrestrial Laser Scanning (TLS) and Photogrammetry) and the results were investigated.

In another study conducted by Maset et al. (2021/b) the usability of the heron lite device was investigated in order to obtain reliable information about cities, public interior and exterior furnishings, and urban areas. The study was carried out in a closed indoor space.
Balenovic et al. (2021) compiled studies in which scanners were used to take forest inventory. They introduced handheld laser scanner systems and their features, and presented examples of their usability in forest inventory studies. Hyyppä et al., (2020) have used the UAV method in conjunction with a portable laser scanner to monitor changes in tree level in Boreal forests.

Volovodova \& Kulik (2020), have studied the archaeological museum in the Matera region in the south of Italy. The usability of the Heron Lite Color laser scanner was investigated for monitoring cultural heritage structures and places. The main results obtained from their study are that the Heron Lite Color mobile laser scanning device can be used for threedimensional modeling of cultural heritage objects in indoor spaces.

\section{Unmanned aerial vehicle (UAV) photogrammetry and structure from motion (SFM)}

With the development and use of UAVs and digital photogrammetric cameras in recent years, the usage of photogrammetry for map production has increased and has become a more cost-effective solution (Mirdan and Yakar, 2017). A dense point cloud can be obtained by directly connecting with ground control points (GCP) created with Global navigation satellite system (GNSS) measurement methods or by using RTK (Real Time Kinematic) GNSS systems on the UAV. Pond volume calculation (Alptekin and Yakar, 2020), rockfall site mapping (Alptekin et al. 2019), shoreline detection (Unel et al. 2020) and landslide site mapping (Kusak et al. 2021) are some of the examples.

While the dense point clouds could only be obtained with LIDAR (Laser Imaging Detection and Ranging) in the past, today the usage of UAVs allows to create high-accuracy orthophoto maps and digital surface model (DSM) (Gonçalves and Henriques, 2015; Peterman, 2015; Bui et al., 2017). The basis of data production in UAV photogrammetry is based on the central projection method. As in Figure 1, the rays coming from an object pass through the focal point in a linear way and fall on the projection plane. In this way, a projection of all objects in the image area is formed on this plane.

In recent years, with the development of UAV and SfM photogrammetry technology, the ability to obtain 3D models of the ground surface has been significantly enhanced (Fonstad et al. 2013; Hugenholtz et al. 2013; Tonkin et al. 2014; Clapuyt et al. and Van Oost 2015; Qu, Huang, and Zhang 2018).

SfM, a measurement method originating from computerized imaging techniques that are gaining popularity and is not very expensive (Westoby et al. 2012; Yakar et al. 2015), is based on the same principles as stereoscopic photogrammetry (Westoby et al. 2012; Barazzetti et al. 2011). In the SfM method, 3D structures are created from a series of overlapping images (Figure 2). 


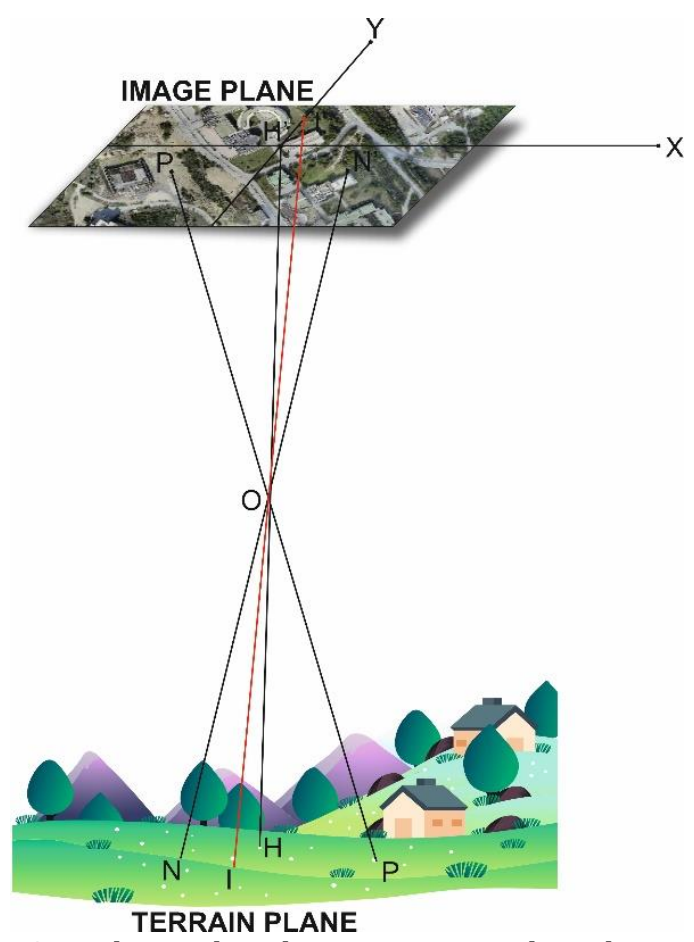

Figure 1. Relationship between ground and image coordinate system
0: Projection (Projection) center
P: Land point
$\mathrm{H}^{\prime}$ : Prime point
$\mathrm{N}^{\prime}$ : Rare point
$\mathrm{H}^{\prime} \mathrm{OH}$ : Principal axis (Uptake axis)
P'OP: Line of projection
I: Focal point

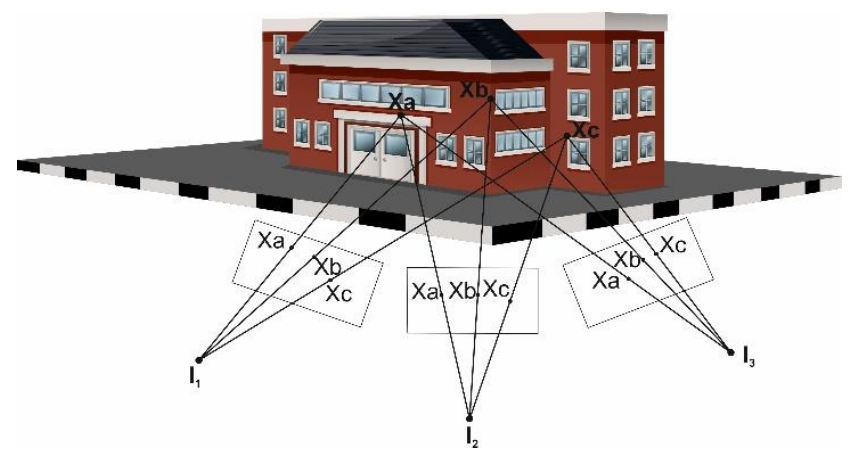

Figure 2. SfM diagram

\section{Wearable mobile laser scanner (WMLS)}

WMLS system is a technique, based on simultaneous localization and mapping (SLAM) algorithm. This technique enables the creation of a map of an unknown environment by passing with distance sensors while simultaneously determining the system location on the map.

These systems are capable of digitizing complex 3D scenarios without a global navigation satellite system (GNSS), thanks to SLAM algorithms (Bailay et al., 2006; Tang et al., 2015; Zeybek, 2021). The quality of the data depends on the rate of penetration and the distance to the object. These devices usually offer centimeter scale accuracy. Although these devices are more suitable for indoor use due to their higher productivity and efficiency than outdoor use, they have been successfully used for reconstructing outdoor scenarios such as cultural heritage, civil engineering and urban inventory.

Working with SLAM algorithm, the device receives data from its sensors (Inertial Measurement Unit (IMU) and odometry) in order to locate where it is in the environment. It uses this data to calculate the best estimate of where geometric objects in the environment (wall, floor, column, etc.) are located. Basically, the SLAM algorithm uses this data to detect the variability of the geometric objects (wall, floor, column, etc.) around a system to create a local coordinate map of the environment and to calculate the best estimate of where it is when determining its location.

\section{Material and method}

\subsection{Ebee unmanned aerial vehicle}

Fixed-wing ebee unmanned aerial vehicle was used within the scope of this study. The appearance of the UAV is shown in Figure 3 and its technical specifications are shown in Table 1 . The technical specifications of the SODA camera used by Ebee UAV are shown in Table 2 and the residual view of the camera is shown in Figure 4.

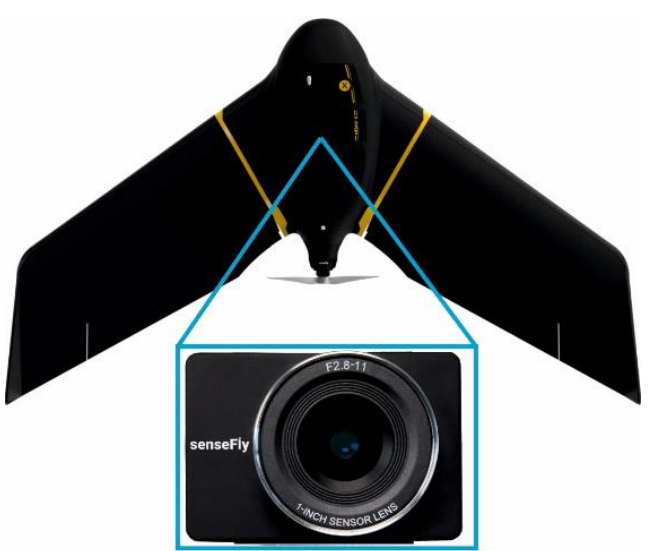

Sensor $(\mathrm{mm}): 12.75 \times 8.5$

Resolution : 20MP

Figure 3. Ebee Plus and overview of the camera.

Table 1. Ebee Plus UAV technical specifications.

\begin{tabular}{llllll}
\hline Wingspan Weight & Camera & Control Sottuare & \multicolumn{3}{c}{ Maximum Fight Time Wing Resistance } \\
\hline $110 \mathrm{~cm}$ & $1.1 . \mathrm{kg}$ & S.0.DA. & Emotion 3 & 59 minute & Up to $45 \mathrm{~km} / \mathrm{h}$ \\
\hline
\end{tabular}

Table 2. Technical specifications of the camera used.

\begin{tabular}{lllll}
\hline Camera Model & Resolution & Focal length & Pixel Size & Precalibrated \\
\hline S.0.D.A. $(10.6 \mathrm{~mm})$ & $5472 \times 3648$ & $10.6 \mathrm{~mm}$ & $2.4 \times 2.4 \mu \mathrm{m}$ & №
\end{tabular}

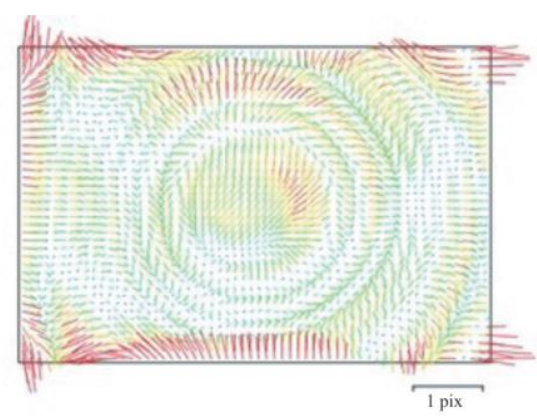

Figure 4. Image residuals for S.O.D.A. (10.6 mm) 


\subsection{Wearable Laser Scanner}

The general view of the WMLS device used in this study is shown in Figure 5., and the technical specifications of the laser device is shown in Table 3.

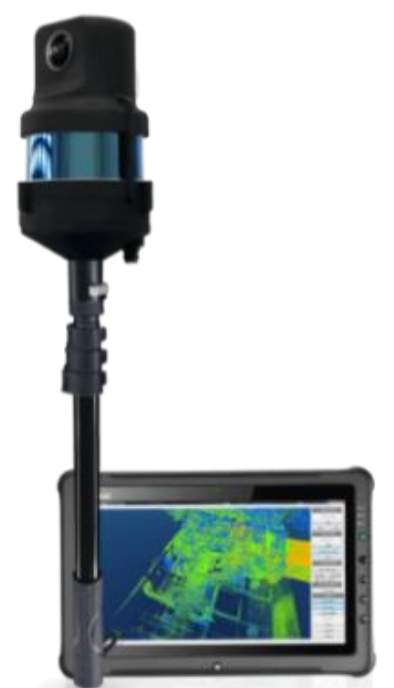

Figure 5. Heron Lite Color Wearable laser scanner overview

The system shown in figure 6 has been taken into account for data collection and management with WMLS. In this context, it is possible to identify a number of methodological stages that characterize an audit: (i) research design (path planning); (ii) data collection (protocol and ground rules); (iii) post processing (SLAM algorithm for calculating sensor trajectory and mapping the environment); and (iv) cartographic product production (three-dimensional and two-dimensional digital models). Figure 6 summarizes the main steps of the applied methodology.

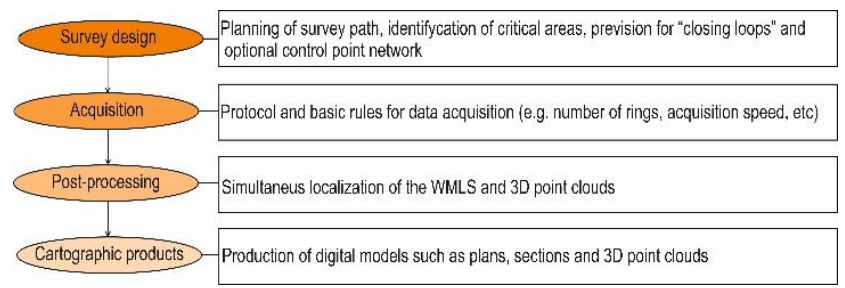

Figure 6. Methodological phases of the procedural pipeline for surveys with a WMLS

Table 3. Technical Performance Specifications of mobile LiDAR Gexcel Heron Lite Color provided by the manufacturer (URL-1).

\begin{tabular}{|c|c|}
\hline $\begin{array}{c}\text { Technical Characteristic of } \\
\text { Gexcel Heron Lite Color }\end{array}$ & Value \\
\hline Brand and type & Velodyne VLP 16 \\
\hline Measurement range & $\begin{array}{c}0.4 \mathrm{~m}-100 \mathrm{~m} \text { indoor or } \\
\text { outdoor }\end{array}$ \\
\hline Measurement speed & $\begin{array}{l}\text { Up to } 300,000 \\
\text { points/second }\end{array}$ \\
\hline $\begin{array}{l}\text { Ranging Accuracy (for } \\
\text { measurements of 10-100 m) }\end{array}$ & $\pm 3 \mathrm{~cm}$ \\
\hline $\begin{array}{l}\text { Absolute accuracy [ } 1 \text { sigma in } \\
\mathrm{cm} \text { ] }\end{array}$ & $\pm 3 \mathrm{~cm}$ \\
\hline Max survey resolution & $\sim 2 \mathrm{~cm}$ \\
\hline $\begin{array}{l}\text { Field of view } \\
\text { (vertical/horizontal) }\end{array}$ & $360^{\circ} \mathrm{V} / 360^{\circ} \mathrm{H}$ \\
\hline
\end{tabular}

\subsection{Data collection}

\subsubsection{UAV data collection}

Seventeen Ground Control Points (GCPs) have been established in the campus area in order to obtain data with the UAV (Figures $7 \mathrm{a}$ and $7 \mathrm{~b}$ ).

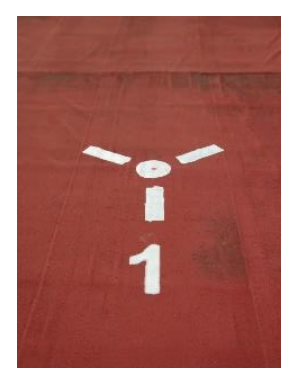

(a)

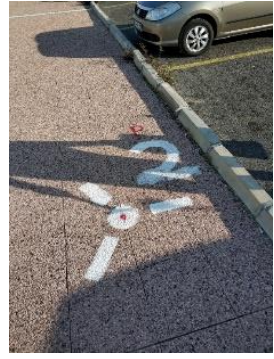

(b)
Figure 7. The study of establishing (a) and (b) Ground Control Points homogeneously on the campus area

While establishing the GCPs, attention was paid to distribute it homogeneously in the working area. After the completion of the GCP establishment process had completed, the coordinates were obtained with the SATLAB Global Positioning System (GPS) device in the ITRF96 datum system (Figure 8a / b).

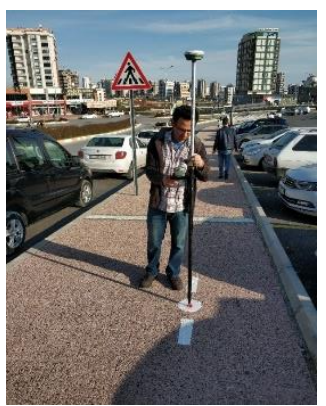

(a)

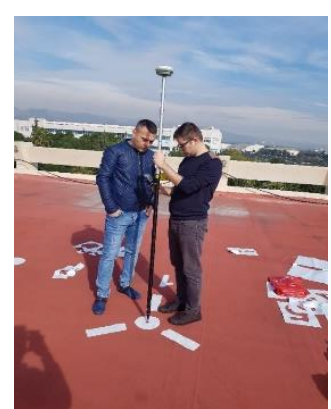

(b)
Figure 8. (a), (b). Coordinate obtaining of GCPs

The coordinates of the GCPs are shown in Table 4.

The flight was performed with 5 Ground Sampling Distance (GSD) and the flight altitude was $212 \mathrm{~m}$. The flight duration lasted 120 minutes and a total of 1218 photographs were taken. Pre-flight preparatory work is shown in Figure 9 (a and b).

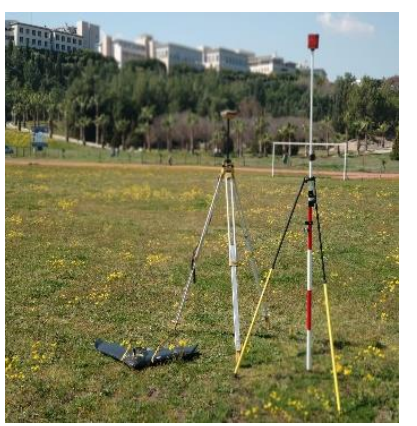

(a)

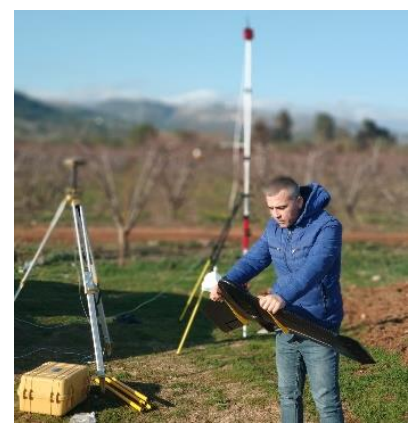

(b)
Figure 9. (a) and (b) Pre-flight preparation procedures 
Table 4. GCP koordinates

\begin{tabular}{cccc}
\hline Nokta & $\mathrm{Y}$ & $\mathrm{X}$ & $\mathrm{Z}$ \\
\hline P.1 & 368698.660 & 4074215.516 & 137.115 \\
P.100 & 368716.714 & 4073616.490 & 101.422 \\
P.101 & 369168.474 & 4073638.694 & 104.272 \\
P.11 & 369080.534 & 4073986.770 & 107.766 \\
P.2 & 369599.618 & 4073675.892 & 80.785 \\
P.3 & 368948.478 & 4073093.430 & 102.594 \\
P.4 & 368306.151 & 4073348.508 & 101.630 \\
P.5 & 367949.748 & 4074037.107 & 135.519 \\
P.50 & 369545.940 & 4074179.552 & 82.676 \\
P.7 & 367699.989 & 4074761.942 & 198.432 \\
P.8 & 369225.418 & 4074742.175 & 110.503 \\
P.9 & 368882.376 & 4074800.483 & 115.018 \\
GCP1 & 368601.763 & 4073364.781 & 135.897 \\
GCP2 & 368503.024 & 4073705.701 & 149.072 \\
GCP3 & 368228.693 & 4074049.062 & 157.892 \\
GCP4 & 367924.452 & 4074293.231 & 176.264 \\
GCP5 & 368746.561 & 4073947.330 & 142.447 \\
\hline
\end{tabular}

\subsubsection{Scanning process with Heron Laser Scanner}

Some issues were taken into consideration in the field study with the WMLS system. First of all, positionbased calibration of the WMLS system was performed before starting the measurement. In this section, the object or objects whose geometry is known to be considered are calibrated at the location. After the calibration process, the area to be scanned is measured at a constant speed. During the scanning, the following suggestions were taken into consideration to obtain accurate and sensitive data.

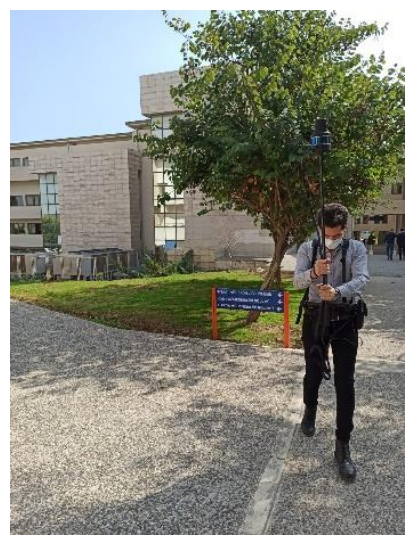

(a)

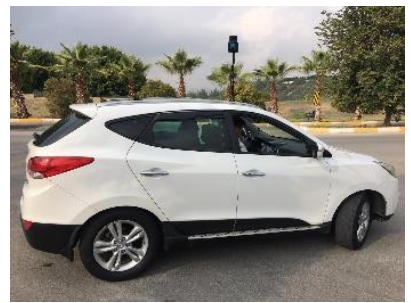

(c)

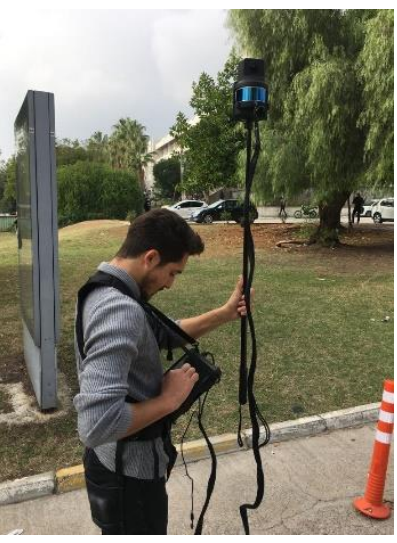

(b)

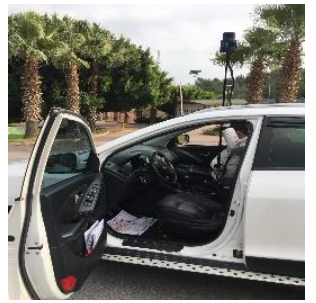

(d)
Figure 10. (a) and (b) Scanning with the wearable laser scanner (c) and (d) using the laser scanner device in the vehicle

- Sudden movements during scanning cause deficiencies or distortions in the data to be obtained. For this reason, the route was followed by avoiding sudden movements.
- Moving objects (human, car, animal, etc.) cause corruption of the point cloud data to be created. In other words, it creates noise in the data. In such cases, it is necessary to avoid moving objects first, but in obligatory cases, the noises should be deleted when the data processing section is passed.

- In narrow areas, the system should not be kept at a distance where the scanned area can be seen.

Pictures of field scanning are shown in Figure 10. a.b.c.d.

In Figure 11a and b, the control of the measured underground lines was performed with a GPS device.

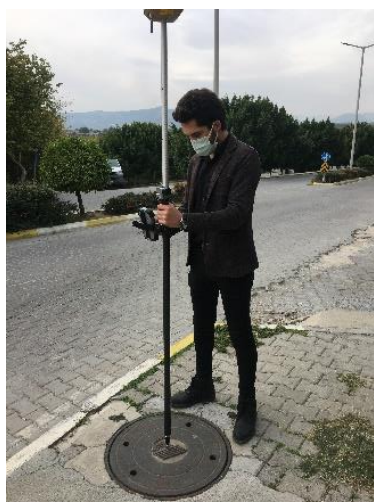

(a)

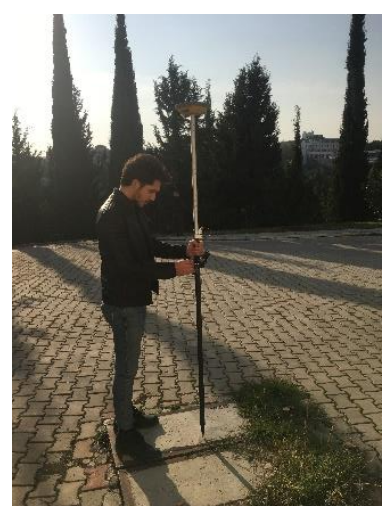

(b)
Figure 11. (a) and (b) Coordinate control of underground lines with GPS device

\section{Data evaluation}

The orthophoto map obtained by the UAV was used as an auxiliary information source to provide a detailed representation of the project. Orthophoto map was produced with Agisoft software.

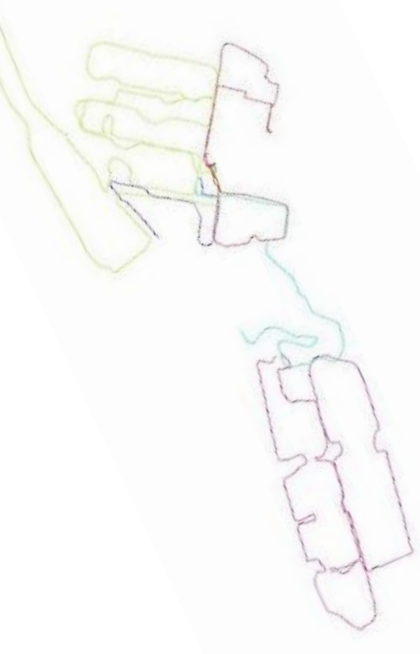

Figure 12. Trajectory measurements performed with the Heron device 
The data obtained from the Heron device were evaluated in Gexcel software. As a result of the evaluation 703468676 points were produced. The route map of the underground lines was marked on the point cloud obtained with the Heron device (Figure 12). These markings were then matched with the orthophoto map obtained by the drone.

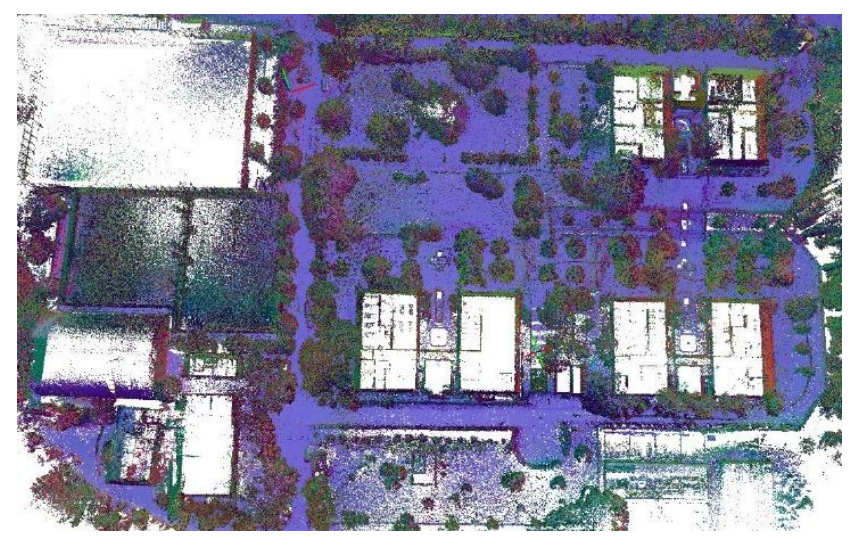

(a)

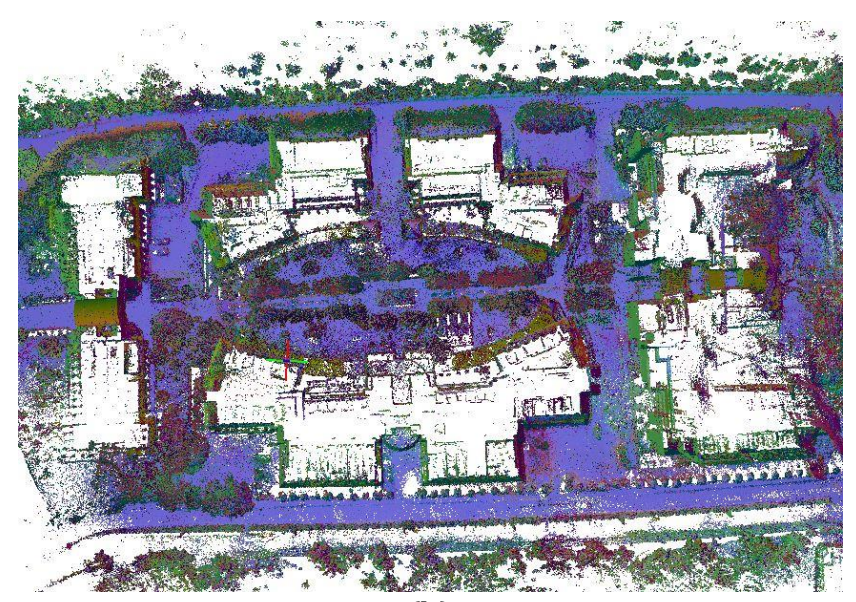

(b)

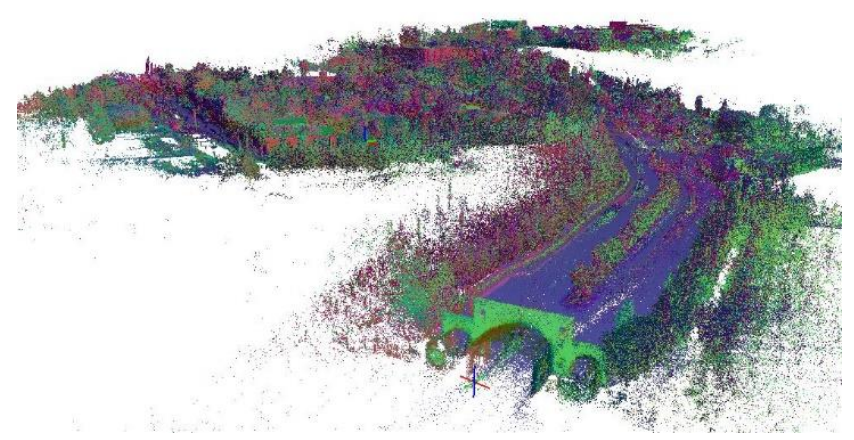

(c)

Figure 13. (a), (b), (c) Point cloud of Mersin University campus area produced by Heron mobile laser device

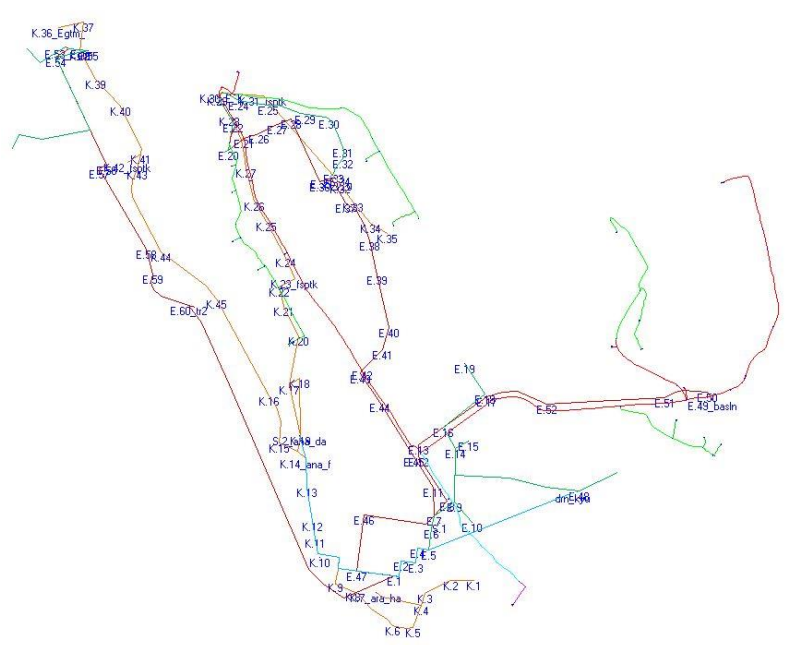

Figure 14. Route map created over the point cloud

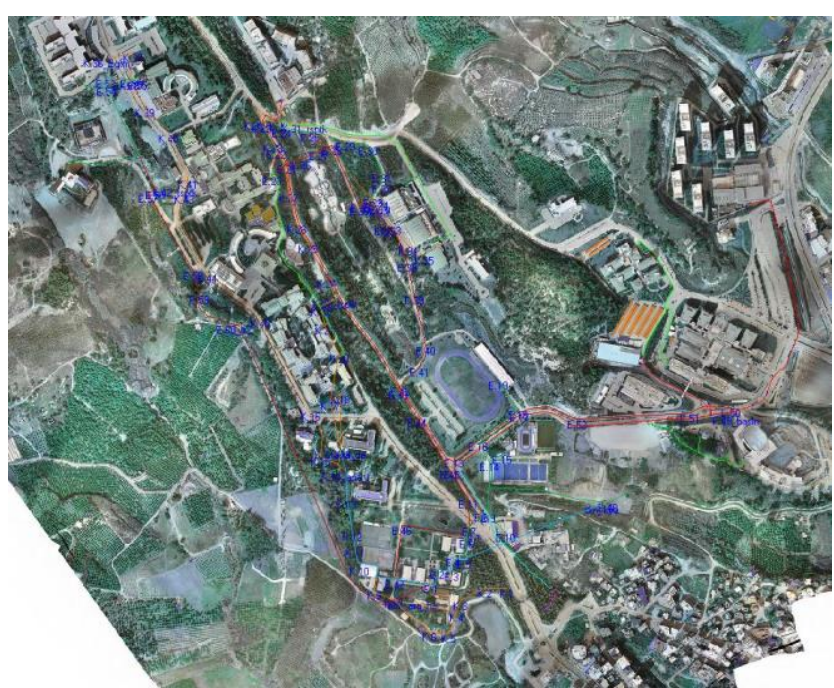

Figure 15. Route map processed on orthophoto map

A legend, shown in Figure 16, has been created about which routes are being used in these mapping studies.

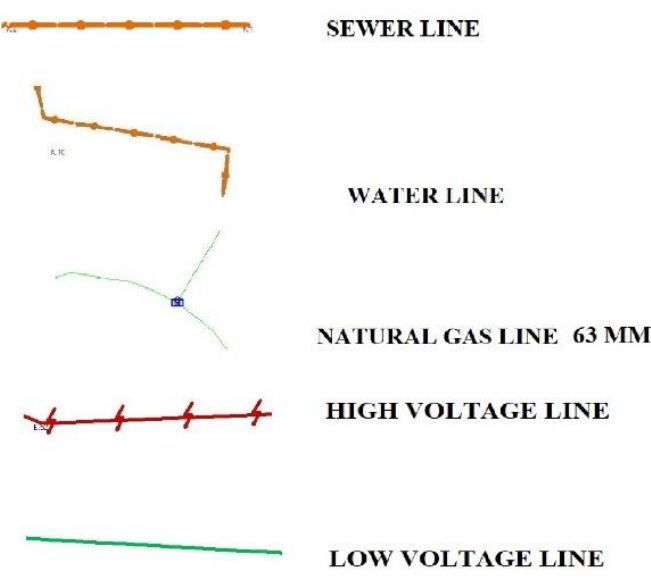

NATURAL GAS LINE $125 \mathrm{MM}$

Figure 16. Legend representation of underground and surface lines 


\section{Conclusion}

The rapidly developing laser scanning technology in recent years has become an acceptable and usable evaluation tool for many applications, as it offers powerful, practical, accurate and reliable solutions. As a result of the scanning process, in addition to the distance and 3D point location information, 3D models that give the scene appearance were obtained by combining the scanning data with the software. Wearable laser scanning technique provides a great advantage over classical measurement methods in obtaining accurate and reliable geometric and metric information by modeling detailed objects or complex scenes with very large data size faster.

Gexcel software caters to professional users. This software includes many more parameters, creates point cloud and mesh triangles without number limit, meets a wide variety of point cloud and mesh generation and editing commands, and supports many geometric applications, making this software among the most powerful 3D modeling software.

Technological developments have shown themselves in the field of engineering as in every field. Due to the rapid progress in measurement technology, heron WMLS has been used in the detection of underground lines (sewage, water and natural gas).

Especially the point cloud of the roads was obtained with the laser scanner. Sewerage, water and natural gas pipelines were determined through the point cloud. These determinations were checked with a GPS device. As a result of this study, maps of the existing infrastructure lines in the campus were created.

When this study is carried out in certain periods, the infrastructure maps will be constantly updated.

\section{Acknowledgement}

This research was supported by Mersin University Scienific Research Project (BAP), Project no: 2020-1AP5-4071

\section{Author contributions}

Ali Ulvi: Conceptualization, Methodology, Software Abdurahman Yasin Yiğit: Data curation, WritingOriginal draft preparation, Software, Validation. Mehmet Özgür Çelik: Software, Investigation Aydın Alptekin: Visualization, Writing-Reviewing and Editing.

\section{Conflicts of interest}

The authors declare no conflicts of interest.

\section{References}

Alptekin A \& Yakar M (2020). Determination of pond volume with using an unmanned aerial vehicle. Mersin Photogrammetry Journal, 2(2), 59-63.

Alptekin A, Çelik M Ö, Doğan Y \& Yakar M (2019). Mapping of a rockfall site with an unmanned aerial vehicle. Mersin Photogrammetry Journal, 1(1), 12-16.
Bailey T \& Durrant-Whyte H (2016). Simultaneous localization and mapping (SLAM): Part II. IEEE Robot. Autom. Mag. 13, 108-117.

Balenović I, Liang X, Jurjević L, Hyyppä J, Seletković A \& Kukko A (2021). Hand-Held Personal Laser Scanning - Current Status and Perspectives for Forest Inventory Application. Croatian Journal of Forest Engineering, 42(1), 165-183. https://doi: 10.5552/crojfe.2021.858

Barazzetti L, Binda L, Scaioni M, Taranto P (2011). Photogrammetric survey of complex geometries with low-cost software: Application to the 'G1' temple in Myson, Vietnam. Journal of Cultural Heritage, 12, 253-262, DOI: 10.1016/j.culher.2010.12.004

Bui D T, Long N Q, Bui X N, Nguyen V N, Van Pham C, Van Le C, Kristoffersen B (2017). Lightweight unmanned aerial vehicle and structure-from-motion photogrammetry for generating digital surface model for openpit coal mine area and its accuracy assessment. In International Conference on GeoSpatial Technologies and Earth Resources, Springer, Cham, 17-33.

Clapuyt F V \& Vanacker K Van Oost (2015). "Reproducibility of UAV-based Earth Topography Reconstructions Based on Structure-from-motion Algorithms." Geomorphology 260: 4-15. doi:10.1016/j.geomorph.2015.05.011.

Fonstad M A, J T Dietrich, B C. Courville J L, Jensen, and P. E. Carbonneau. (2013). Topographic Structure from Motion: A New Development in Photogrammetric Measurement. Earth Surface Processes and Landforms 38 (4): 421-430. doi:10.1002/esp.3366.

Gonçalves J A \& Henriques R (2015). UAV photogrammetry for topographic monitoring of coastal areas. ISPRS Journal of Photogrammetry and Remote Sensing, 104, 101-111.

Hugenholtz C H K, Whitehead O W, Brown T E, Barchyn B J, Moorman A, Leclair K, Riddell \& $\mathrm{T}$ Hamilton (2013). Geomorphological Mapping with a Small Unmanned Aircraft System (SUAS): Feature Detection and Accuracy Assessment of a Photogrammetrically-derived Digital Terrain Model. Geomorphology 194: 16-24. doi:10.1016/j.geomorph.2013.03.023.

Hyyppä E, Yu X, Kaartinen H, Hakala T, Kukko A, Vastaranta M \& Hyyppä J (2020). Comparison of Backpack, Handheld, Under-Canopy UAV, and Above-Canopy UAV Laser Scanning for Field Reference Data Collection in Boreal Forests. Remote Sensing, 12(20), 3327. https://doi.org/10.3390/rs12203327

Karataş K \& Bıyık C (2008/2). Jeodezi, Jeoinformasyon ve Arazi yönetimi dergisi, Sayı,99, 5-11

Maset E, Cucchiaro S, Cazorzi F, Crosilla F, Fusiello A \& Beinat A (2021/a). Investigating The Performance of a Handheld Mobıle Mapping System in Different Outdoor Scenarios. XXIV ISPRS Congress. https://doi.org/10.5194/isprs-archives-XLIII-B12021-103-2021

Maset E, Scalera L, Beinat A, Cazorzi F, Crosilla F, Fusiello A \& Gasparetto A (2021/b). Proceedings of I4SDG 
Workshop 2021. I4SDG 2021. Mechanisms and Machine Science, vol 108. Springer, Cham. https://doi.org/10.1007/978-3-030-87383-7_32

Mırdan 0 \& Yakar M (2017). Tarihi Eserlerin İnsansız Hava Aracı ile Modellenmesinde Karşılaşılan Sorunlar. Geomatik, 2 (3), 118-125. DOI: 10.29128/geomatik.306914

Peterman V (2015). Landslide activity monitoring with the help of unmanned aerial vehicle. The International Archives of Photogrammetry, Remote Sensing and Spatial Information Sciences, 40(1/W4), 215-218.

Qu Y, Huang J \& Zhang X (2018). Rapid 3D Reconstruction for Image Sequence Acquired from UAV Camera. Sensors, 18: 225.

Tang J, Chen Y, Chen L, Liu J, Hyyppä J, Kukko A, Chen R (2015). Fast fingerprint database maintenance for indoor positioning based on UGV SLAM. Sensors, 15, 5311-5330.

Tonkin T N, Midgley N G, Graham D J \& Labadz J C (2014). The Potential of Small Unmanned Aircraft Systems and Structure-from-motion for Topographic Surveys: A Test of Emerging Integrated Approaches at Cwm Idwal, North Wales. Geomorphology 226: 35-43. doi:10.1016/j. geomorph.2014.07.021.
URL-1: https://gexcel.it/en/solutions/heron-portable3d-mapping-system (15.11.2021)

Ünel F B, Kuşak L, Çelik M Ö, Alptekin A \& Yakar M (2020). Kıyı Çizgisinin Belirlenerek Mülkiyet Durumunun İncelenmesi. Türkiye Arazi Yönetimi Dergisi, 2(1), 33-40.

Volovodova A V \& Kulik E N (2020). Using Mobile Laser Scanning Data for Formation of Spatial Base for Monitoring of Cultural Heritage Objects. UDC Handbook,528:7:528.8. https://10.33764/2618981X-2020-6-1-80-86

Westoby M J, Brasington J, Glasser N F, Hambrey M J, Reynolds J M (2012). Structure-from-Motion' photogrammetry: A lowcost, effective tool for geoscience applications. Geomorphology, 179, 300314, DOI: $10.1016 /$ j.geomorph.2012.08.021

Yakar M, Orhan O, Ulvi A, Yiğit A Y \& Yüzer M M (2015). Sahip Ata Külliyesi Rölöve Örneği. TMMOB Harita ve Kadastro Mühendisleri Odası, 10.

Zeybek M (2021). Accuracy assessment of direct georeferencing UAV images with onboard global navigation satellite system and comparison of CORS/RTK surveying methods. Measurement Science and Technology 